\title{
Comparative Study of Osseous Alignment in Isolated Tripod Zygomatic Bone Fracture Osteosynthesis At Frontozygomatic Suture Versus Zygomaticomaxillary Suture
}

\author{
Usman Qadir Khan, Qaimuddin Shaikh, Madiha Khalid, Zahoor Ahmed Rana, Sadia Nazir, Nadia Ambreen
}

\section{ABSTRACT}

Background: Zygomatic fractures constitute the second leading facial skeleton fractures, after fractures in the nasal bone. The treatment for zygomatic fractures has been more advanced with various treatment methods. Fixation has been used sporadically by few surgeons ZMC region at frontozygomatic suture and zygomatic buttress. Objective: To compare the osseous alignment in isolated tripod zygomatic bone fracture with onepoint osteosynthesis at frontozygomatic suture versus zygomaticomaxillary suture. Study Design: Comparative study. Settings: Department of Oral and Dental Surgery, Shaikh Zayed Medical College Hospital Rahim Yar Khan-Pakistan. Duration: From July 2016 to June 2017. Methodology: Patients with isolated tripod zygoma fracture were included in this study. The patients were allocated two different group's i.e; group (A), with osteosynthesis at the site of zygomaticofrontal suture and group $(B)$, at zygomaticomaxillary suture site. Each group carried 25 patients equally. Preoperatively, the diagnosis of displaced zygoma fractures was established following clinical and radiographical examination via 3-D C.T scan imaging technique. The osseous alignments were noted in the first follow up visit and more visits upto 3 weeks. Results: The predominant age group in the study was mainly found to be in third decade of life (52\%). Male gender represented the majority (72\%) in the study. The post-operative osseous alignment in group (B) patients, (92\%) were observed more stable and better than group (A), (76\%) in all follow up visits. Conclusion: Single Point fixation of isolated tripod zygoma fracture at either site; zygomaticofrontal suture or zygomaticomaxillary suture may give satisfactory results with a mild difference in post-operative osseous alignment if reduced properly, but slightly better in zygomaticomaxillary site. Good results can be achieved of zygoma fracture both cosmetically and functionally if it is treated within a week.

Keywords: Tripod zygomatic bone fracture, Frontozygomatic suture, Zygomaticomaxillary suture.

Corresponding Author Submitted for Publication: 03-08-2019 Accepted for Publication: 13-10-2019

DR. USMAN QADIR, Associate Professor of Oral \& Maxillofacial Surgery, Shaida Islam Medical and Dental College Lodhran-Pakistan. Contact / Email: +92 313-2851728, drkhan381@gmail.com

Citation: Khan UQ, Shaikh Q, Khalid M, Rana ZA, Nazir S, Ambreen N. Comparative Study of Osseous Alignment in Isolated Tripod Zygomatic Bone Fracture Osteosynthesis At Frontozygomatic Suture Versus Zygomaticomaxillary Suture. APMC 2020;14(1):28-31.

\section{INTRODUCTION}

The Zygomatic fractures constitute the second leading facial skeleton fractures, after fractures in the nasal bone. ${ }^{1}$ Any deformity by fracture can result into different cosmetic and functional problems. The common causes of zygoma fracture are interpersonal violence, road traffic accidents (RTAs), sports injuries, gun shot and occupational injuries. ${ }^{2}$ The clinical signs and symptoms include; swelling, subconjunctival hemorrhage diplopia, periorbital ecchymosis, paresthesia, soft tissue trauma and facial deformity. ${ }^{3}$ Occasionally restriction of opening of the mouth and limited movement of lateral jaw were also observed. Zygomatic bone fractures may be minimized by intra-oral or extra-oral intervention. Although there are several approaches are in uses to decrease the fractured zygoma. ${ }^{4}$ To overcome these short comings open reduction method was stated to have a better assess and appropriate anatomical bony alignment. Moreover, these reduced fractures also needed to have some fixation to avoid the functional and post-operative cosmetic deformities. In contrast to wire fixation to manage zygomatic fractures, various experimental and clinical trials have found good indications of superiority as well as improved long term stability of fracture by using plating device ${ }^{5,6}$ Thus, in this modern era, all of these disadvantages of the wiring method have been practically obsolete by the development and innovation of the titanium plating device. ${ }^{7}$ Modern traumatology began with the introduction of osteosynthesis, a significant advancement in craniomaxillofacial surgical procedure. Tripod relocated zygomatic fractures are usually fixed either alone or in conjunction with an inflexible internal fixation at the infraorbital rim (IOR), zygomaticomaxillary buttress (Z.M) and frontozygomatic suture (F.Z). ${ }^{9}$ Infraorbital rim fixation usually associates with conditions of poor aesthetic outcomes as well as miniplate intolerance to the patients. This option can possibly not be preferred for osteosynthesis, because of no fully functioning load is present at his site and also the bone is very thin that just a few screw threads can anchor on it. ${ }^{8}$ Fixation of miniplate at frontozygomatic suture provides better results of osseous alignment with the exposure of limited incision, good vision and re-establishment of the vertical height of zygoma. But this site has also psychologically effect of plate palpability to an individual post-operatively. Some of the authors also argue to fix the miniplate at zygomaticomaxillary buttress, as it counters the effect of strong masseter muscle pull that ultimately may lead to inferior and lateral rotation of the zygoma. ${ }^{10}$ Hardware can be removed later on without any cosmetic problem. At this site there could be chances of maxillary sinus opening due to its thin bony structure and close approximity with the zygomaticomaxillary buttress. So, the surgeon has to be careful 
during open reduction and internal fixation at this region. ${ }^{11}$ No comprehensive study has yet been found in the local literature to compare the results of one-point osteosynthesis at frontozygomatic suture versus zygomaticomaxillary buttress suture in treating the zygomatic bone fractures. So, in the light of above cited reasons this study intended to find out the differences between one-point osteosynthesis at frontozygomatic suture versus zygomaticomaxillary suture for the osseous alignment in isolated tripod zygomatic bone fracture.

\section{METHODOLOGY}

\section{Study Design: This was a comparative study}

Settings: Department of Oral and Dental Surgery, Shaikh zayed Medical College Hospital Rahim Yar Khan

Duration: From July 2016 to June 2017.

Sample Technique: Non probability consecutive sampling Inclusion Criteria: Patients with either of gender, age range from 18 to 51, having isolated tripod zygomatic bone fracture reporting within seven days of injury were included.

Exclusion Criteria: Patients with bony diseases (Metabolic, Neoplastic and inflammatory), Zygomatic bone fracture associated with other facial bones fracture., already treated zygomatic bone fracture, Immunocompromised patients and Comminuted zygoma fracture were excluded.

Data Collection Procedure: Medical history, clinical examination and radiographic evaluations were done of each patient. Routine radiographs of zygoma fracture; occipitomental and submentovertex views were done. O.P.G was also taken to see the impingement of zygomatic arch over the coronoid process. A 3 D C.T scan was advised pre- and post-operatively at one and three weeks to assess the osseous alignment of isolated tripod zygoma fractures. The photographic evaluation was done to see the aesthetic appearance. Patients fulfilling the inclusion criteria were divided into two groups. Outcome of the surgical procedure was explained to every patient and informed consent was taken before surgery. Pre-operative laboratory investigations and fitness for general anesthesia were carried out for each of the patient before surgery. All the patients were treated under general anesthesia in elective list. Group $(A)$ was treated by osteosynthesis with titanium microplate at zygomaticofrontal suture after reduction by Gillie's approach. Group (B) was treated by osteosynthesis with titanium microplate at zygomaticomaxillary buttress after reduction by keen's approach. Osseous alignment of all patients was checked by 3D C.T scan of face after one week and three weeks of follow up periods. All the data was collected via self-made proforma.

Statistical Analysis: Data was recorded and analyzed in SPSS version 20.0. Qualitative variables like were calculated as frequencies and percentages. Mean and Standard deviation were calculated for quantitative variables like age. Chi-square test was used and a $\mathrm{P}<0.05$ was taken as significant.

\section{RESULTS}

Out of total patients $36(72 \%)$ were males and $14(28 \%)$ were females. Most common age was 31-40 years in both groups.
Right side fracture was observed in $44 \%$ and left side was $56 \%$. Type IIA and IIB fractures were most common in both groups. Results regarding age, gender, site of fracture and type of fracture were statistically insignificant, as shown in table.1

Post-operative osseous alignment after one week and three weeks of follow up periods was noted in both groups as shown below in tables 2 and 3 .

Table 1: Demographic characteristics of patients $n=50$

\begin{tabular}{|c|c|c|c|c|}
\hline \multicolumn{2}{|c|}{ Variables } & Group A & Group B & $\begin{array}{c}\text { P. } \\
\text { value }\end{array}$ \\
\hline \multirow{5}{*}{$\begin{array}{l}\text { Age } \\
\text { groups }\end{array}$} & $>20$ years & $3(12.0 \%)$ & $2(8.0 \%)$ & \multirow{5}{*}{0.889} \\
\hline & $20-30$ years & $5(20.0 \%)$ & $4(16.0 \%)$ & \\
\hline & $31-40$ years & $12(48.0 \%)$ & $12(48.0 \%)$ & \\
\hline & $41-50$ years & $5(20.0 \%)$ & $7(28.0 \%)$ & \\
\hline & Total & $25(100.0 \%)$ & $25(100.0 \%)$ & \\
\hline \multirow{3}{*}{ Gender } & Males & $17(68.0 \%)$ & $19(76.0 \%)$ & \multirow{3}{*}{0.529} \\
\hline & Females & $8(32.0 \%)$ & $6(24.0 \%)$ & \\
\hline & Total & $25(100.0 \%)$ & $25(100.0 \%)$ & \\
\hline \multirow{3}{*}{$\begin{array}{c}\text { Site of } \\
\text { fracture }\end{array}$} & Right & $10(40.0 \%)$ & $12(48.0 \%)$ & \multirow{3}{*}{0.569} \\
\hline & Left & $15(60.0 \%)$ & $13(52.0 \%)$ & \\
\hline & Total & $25(100.0 \%)$ & $25(100.0 \%)$ & \\
\hline \multirow{6}{*}{$\begin{array}{l}\text { Type of ZF } \\
\text { fracture }\end{array}$} & $\| A$ & $9(36.0 \%)$ & $7(28.0 \%)$ & \multirow{6}{*}{0.806} \\
\hline & $\| \mathrm{B}$ & $11(44.0 \%)$ & $9(36.0 \%)$ & \\
\hline & IIIA & $3(12.0 \%)$ & $5(20.0 \%)$ & \\
\hline & IIIB & $1(4.0 \%)$ & $2(8.0 \%)$ & \\
\hline & IIIC & $1(4.0 \%)$ & $2(8.0 \%)$ & \\
\hline & Total & $25(100.0 \%)$ & $25(100.0 \%)$ & \\
\hline
\end{tabular}

Table 2: Post-operative osseous alignment of patients $n=50$

\begin{tabular}{|c|c|c|c|c|}
\hline \multicolumn{2}{|c|}{$\begin{array}{c}\text { Post -operative } \\
\text { Osseous Alignment }\end{array}$} & Group A & Group B & $\begin{array}{c}\text { P- } \\
\text { value }\end{array}$ \\
\hline \multirow{2}{*}{$\begin{array}{c}\text { After one } \\
\text { week }\end{array}$} & Aligned & $21(84.0 \%)$ & $23(92.0 \%)$ & \multirow{2}{*}{0.384} \\
\cline { 2 - 4 } & Malaligned & $04(16.0 \%)$ & $02(08.0 \%)$ & \\
\cline { 2 - 4 } & Total & $25(100.0 \%)$ & $25(100.0 \%)$ & \\
\hline \multirow{2}{*}{$\begin{array}{c}\text { After three } \\
\text { weeks }\end{array}$} & Aligned & $23(92.0 \%)$ & $24(96.0 \%)$ & \multirow{2}{*}{0.552} \\
\cline { 2 - 4 } & Malaligned & $02(08.0 \%)$ & $01(04.0 \%)$ & \\
\cline { 2 - 4 } & Total & $25(100.0 \%)$ & $25(100.0 \%)$ & \\
\hline
\end{tabular}

Table 3: Postoperative Osseous Alignment of patients $n=50$

\begin{tabular}{|c|c|c|c|c|c|c|c|}
\hline \multirow{2}{*}{\multicolumn{2}{|c|}{$\begin{array}{c}\text { Post -operative } \\
\text { Osseous Alignment }\end{array}$}} & \multicolumn{5}{|c|}{ Type of fractures } & \multirow{2}{*}{$\begin{array}{c}\text { p- } \\
\text { value }\end{array}$} \\
\hline & & $\| A$ & IIB & IIIA & IIIB & IIIC & \\
\hline \multirow{3}{*}{ Group A } & Aligned & 09 & 10 & 03 & 1 & 0 & \multirow{3}{*}{0.453} \\
\hline & Malaligned & 00 & 01 & 00 & 0 & 01 & \\
\hline & Total & 09 & 11 & 03 & 01 & 01 & \\
\hline \multirow{3}{*}{ Group B } & Aligned & 1 & 1 & 07 & 8 & 7 & \multirow{3}{*}{0.652} \\
\hline & Malaligned & 0 & 0 & 0 & 1 & 0 & \\
\hline & Total & 1 & 1 & 7 & 9 & 7 & \\
\hline
\end{tabular}

\section{DISCUSSION}

Zygoma fracture can be fixed at different points i.e; zygomaticofrontal suture, infraorbital margin and zygomaticomaxillary suture. ${ }^{12}$ The infraorbital rim is an important site in the assessment of accurate reduction of the zygomatic complex. But it cannot be an ideal option in miniplate osteosynthesis because this site is very thin and only few screw 
threads can be fixed here and the palpability of the plate is unacceptable to the patient. ${ }^{13}$ The infraorbital exploration may cause problems in lower eyelid e.g. perceptible and ectropion a scar. The frontozygomatic suture line represents a thick bone as compared to other sutures lines for rigid fixation. Patient's scar mark may camouflage with natural eye- brow but unfortunately, plates in this area are palpable. The chance of opening of many facial spaces is another disadvantage. In this study the author also determined the side of the zygoma fracture in this study. The left side of zygoma was found to be affected more $28(56 \%)$ than the right side 22 (44\%). Our result is in line with the findings of Cheema et al, ${ }^{14}$ who stated that left side $(54 \%)$ of the zygoma was more likely to be fractured as compared to right side (46\%). Marcin et al ${ }^{15}$ reported a high rate of zygoma fracture at left side. It could be because majority of people use their right-hand during violence or during involuntary moment, they take its support. Therefore, naturally they generally punch at the left side of the victim's face with right hand in fighting. ${ }^{16}$

In this study out of all cases $36(72 \%)$ were males and $14(28 \%)$ were females. Most common age was $31-40$ years in both groups. Similarly Balakrishnan $\mathrm{K}$ et al ${ }^{171}$ reported that mostly fracture were seen in age group of 20 and 40 years and males were higher as compared to females. In this study road traffic accident was the commonest etiology. Similarly Ansari SR et al ${ }^{20}$ reported that the RTA was the commonest etiology of zygomatic bone fracture $76.5 \%$

In current study osseous alignment of treated zygoma fracture was observed using 3-D C.T scan following follow up period 1 and 3 weeks of visits, which was slightly high in group $B$ and malalignment was high in group $A$, while results were statistically insignificant $(p=384)$. No similar recent studies found on this exit comparison.

In this current study it was noticed that six (24\%) patients in group (A) reported with osseous malalignment in post-operative periods. The result of this series is also compatible with the study of Kovacs et $\mathrm{al}^{18}$, in 52 patients in which he achieved better post-operative osseous alignment in all patients except five patients who had malalignment in the follow up visits. Another study was conducted by Mohammadinezhad et al ${ }^{19}$, where he fixed the mini titanium plates at zygomaticofrontal site in 17 patients and found osseous malalignment only in three patients in follow up periods. The author could not find sufficient data, regarding three weeks post-operative follows up, available to support a single point fixation of zygoma at zygomaticofrontal site. So, in the present study the possible explanation of malalignment in six patients might have occurred due to the pulling action of masseter muscle over zygomaticomaxillary buttress, as it was not fixed in this group. The tripod zygoma fracture was fixed in group (A) at zygomaticofrontal suture so significant malalignment of treated zygoma was seen in follow up visits at zygomaticomaxillary suture area as compared to infraorbital margin.

In this study two patients (8\%) of group B had osseous malalignment in post-operative follow up visits. Another study was carried out by Courtney ${ }^{20}$, where he noticed osseous malalignment in four patients out of fifty patients in follow up visits. The author observed that the buttress site is considered to be the better site of fixation of zygoma fracture as compared to zygomaticofrontal and infraorbital sites due to the direct counter effect of masseter muscle pull. ${ }^{21}$ In group (B), the osseous malalignment in two patients might have happened due to temporalis muscle over the zygomatic complex. But some of its fibers might cause some distraction forces at zygomaticofrontal site as it was not fixed. ${ }^{22}$

\section{CONCLUSION}

Single point fixation of isolated tripod zygoma fracture at either site; zygomaticofrontal suture or zygomaticomaxillary area may give satisfactory results with a mild difference in post-operative osseous alignment if reduced properly, slightly better in zygomaticomaxillary site, but two points fixation would be a better option.

We can achieve good result of zygoma fracture both cosmetically and functionally if it is treated within a week.

The patient's comfort and esthetic can be accomplished slightly better at zygomaticomaxillary site.

The main etiological factor of zygoma fracture in our set up is road traffic accident. It can be reduced by awareness and implementation of traffic legislation among the public.

\section{LIMITATIONS}

Single Centre and small sample size study

\section{SUGGESTIONS / RECOMMENDATIONS}

Further multi center studies are required on this comparison. To achieve good result of zygoma fracture it should be treated within a week.

Awareness and implementation of traffic legislations should be done among the public to decrease the morbidity.

\section{CONFLICT OF INTEREST / DISCLOSURE}

No conflict of interest.

\section{ACKNOWLEDGEMENTS}

Authors have acknowledged to Rizwan Ali for their technical support.

\section{REFERENCES}

1. Alamgir, Hameed H, Hussain Shah SM. Frequency, etiology and characteristics of zygomatic complex fractures. Pak Oral Dental J. 2013;33;2;240-3.

2. Assiri ZA, Almaijid EA, Alfadhel AK. Retrospective radiological evaluation to study the prevalence and pattern of maxillofacial fracture among Military personal at Prince Sultan Military Medical City [PSMMC], Riyadh: An institutional study. Saudi Dent J. 2020;32(5):242-9.

3. Chouinard AF, Troulis MJ, Lahey ET. The acute management of facial fractures. Current Trauma Reports. 2016;2(2):55-65.

4. Thangavelu K, Ganesh NS, Kumar JA, Sabitha S. Evaluation of the lateral orbital approach in management of zygomatic bone fractures. J Nat Sci Biol Med. 2013;4(1):117-21.

5. Parashar A, Sharma RK, Makkar S. Rigid internal fixation of zygoma fractures: A comparison of two-point and three-point fixation. Indian J Plast Surg. 2007;1;40(1):18-24. 
6. Hussain S, Rizvi ZA. Optimization of management for zygomatic complex fractures: a study at tertiary care teaching hospital in Pakistan. J Pak Dent Assoc. 2010;19(3):164-8.

7. Hollier LH, Thornton J, Pazmino P. The management of orbitozygomatic fracture, Plast Reconstr Surg. 2003;(11):238693.

8. Sridhar P, Sandeep S, Prasad K, Lalitha RM, Ranganath K, Munoyath KS. Comparative evaluation of single point fixation at zygomatic buttress and fronto zygomatic rim in zygomatic complex fractures-a prospective study. J Dent Orofacial Res. 2017;13(2):27-39.

9. Si J, Ren R, Wang M. Three-point fixation of displaced tripod zygomaticomaxillary complex fracture: a modified surgical technique. Int J Clin Exp Med. 2017;10(4):7199-203.

10. Kelley $P$, Hopper R, Gruss J. Evaluation and treatment of zygomatic fractures. Plast Reconstr Surg. 2007;120(7 Suppl 2):5S-15S.

11. Tollefson TT. Zygomaticomaxillary Complex Fractures. Medscape2019;

https://emedicine.medscape.com/article/867687-treatment

12. Bacelli R, Quarato D, Matarazzo G. Aesthetics positioning of rigid internal fixation in tripod zygomatic fractures: An innovative surgical technique, J Craniofac Surg. 2009;20(3)724-25.

13. Tadj A, Kimble FW. Fractured zygomas. ANZ J Surg. 2003;73(12):49-54.
14. Cheema SA. Zygomatic bone fracture. JCPSP 2004;14(6):337-9.

15. Czerwinsiki $\mathrm{M}$, Lee $\mathrm{CH}$. The rationale and technique of endoscopic approach to the zygomatic arch in facial trauma, Facial Plast Surg Clin North Am. 2006;14(1):37-43.

16. Ansari SR, Shah SM, Rehman B. Pattern of zygomatic bone fractures and treatment modalities: a study. Pak Oral Dental J. 2010;1;30(1):36-40.

17. Balakrishnan K, Ebenezer V, Dakir A, Kumar S, Prakash D. Management of tripod fractures (zygomaticomaxillary complex) 1 point and 2 point fixations: A 5-year review. J Pharm Bioallied Sci. 2015;7(Suppl 1): S242-S247.

18. Kovacs AF, Ghahremani M. Minimization of zygomatic complex fracture treatment. Int J Oral Maxillofac Surg. 2001;30(5):380-83.

19. Mohammadinezhad $C$. Evaluation of a single miniplate use in treatment of zygomatic bone fracture. J Craniofac Surg. 2009;20(5):1398-402.

20. Courtney DJ. Upper buccal Sulcus approach to the management of the zygomatic complex: A retrospective study of 50 cases. $\mathrm{Br}$ J Oral Maxillofac Surg. 1999;37(6):464-6.

21. Kelley P, Hopper R, Gruss J. Evaluation and treatment of zygomatic fracture, Plastic Reconst Surg 2007;120(7):135-40.

22. Barry CP, Ryan WJ, Stassen LF. Anatomical study of factors contributing to zygomatic complex fracture instability in human cadavers. Plast Reconstr Surg. 2007;119 (2): 637-40.

\section{AUTHORSHIP AND CONTRIBUTION DECLARATION}

AUTHORS Contribution to The Paper Signatures

\section{Dr. Usman Qadir Khan}

Associate Professor, Oral \& Maxillofacial Surgery

Department, Shaida Islam Medical and Dental

College Lodhran

Conduct the Study as Principle Author

Ex. Assistant professor

Shaikh Zayed Medical College Hospital Rahim Yar

Khan Pakistan

\section{Dr. Qaimuddin Shaikh}

Associate Professor, Oral \& Maxillofacial Surgery

Department, Bibi Aseefa Dental College, Shaheed

Mohtarma Benazir Bhutto Medical University

Contribution in Data Collection and Manuscript Writing

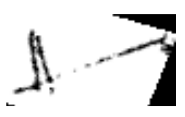

Larkana, Pakistan

\section{Dr. Madiha Khalid}

Senior Lecturer, Oral Biology Department, Isra

Medical University Hospital, Hyderabad Pakistan

\section{Prof. Dr. Zahoor Ahmed Rana}

Professor, Head of Oral \& Maxillofacial Surgery

Department, Pakistan Institute of Medical Sciences

Islamabad Pakistan

\begin{tabular}{l}
\hline Dr. Sadia Nazir \\
Dental Surgeon \\
Shaikh Zayed Medical College Hospital Rahim Yar \\
Khan Pakistan
\end{tabular}

\section{Contribution in Data Analysis and Manuscript Writing}

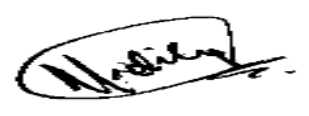

Review the Manuscript and Guideline in Data Analysis

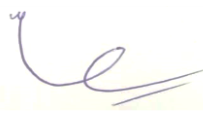

\section{Dr. Nadia Ambreen}

Dental Surgeon

Shaikh Zayed Medical College Hospital Rahim Yar

Contribution in manuscript writing

Contribution in data collection

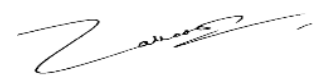

Khan Pakistan 